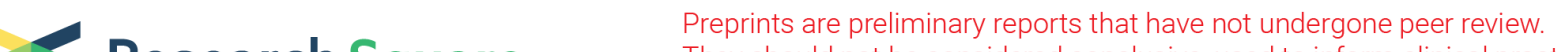

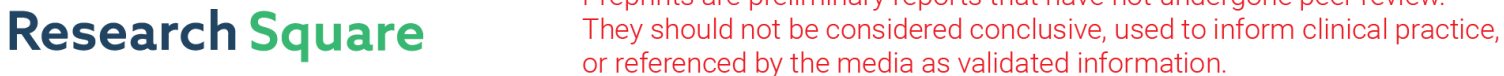

\section{Seasonal Expression of Extracellular Signal Regulated Kinases in the Colon of Wild Ground Squirrels (Spermophilus Dauricus)}

\section{Yue Song}

Beijing Forestry University College of Biological Sciences and Biotechnology

\section{Xiaoying Yang}

Beijing Forestry University College of Biological Sciences and Biotechnology

\section{Xueying Zhang}

Beijing Forestry University College of Biological Sciences and Biotechnology

Jueyu Zhu

Beijing Forestry University College of Biological Sciences and Biotechnology

\section{Yixin Chen}

Beijing Forestry University College of Biological Sciences and Biotechnology

\section{Fuli Gao}

Beijing Forestry University College of Biological Sciences and Biotechnology

Haolin Zhang

Beijing Forestry University College of Biological Sciences and Biotechnology

\section{Yingying Han}

Beijing Forestry University College of Biological Sciences and Biotechnology

\section{Qiang Weng}

Beijing Forestry University College of Biological Sciences and Biotechnology

Zhengrong Yuan ( $\nabla$ zryuan@bjfu.edu.cn )

Beijing Forestry University

\section{Research Article}

Keywords: extracellular signal regulated kinase, colon, wild ground squirrel, seasonal adaption

Posted Date: September 13th, 2021

DOI: https://doi.org/10.21203/rs.3.rs-841280/v1

License: (c) (1) This work is licensed under a Creative Commons Attribution 4.0 International License.

Read Full License 
Version of Record: A version of this preprint was published at Molecular Biology Reports on January 18th, 2022. See the published version at https://doi.org/10.1007/s11033-021-07042-0. 


\section{Abstract}

Background: The aim of this study was to explore the localization and expression of extracellular signal regulated kinase/phospho-extracellular signal regulated kinases (ERK/pERK) in the colonic tissue of wild ground squirrels (Spermophilus dauricus) in the breeding season and the non-breeding season.

Methods and Results: Hematoxylin-eosin staining, immunohistochemistry, real-time quantitative PCR and Western blot were used in this study. The histological results showed that the diameter of the colon lumen in the non-breeding season was larger than that in the breeding season, and the number of glandular cells in the non-breeding season was also more than those in the breeding season. The immunochemical results showed that ERK $1 / 2$ was expressed in the cytoplasm of goblet cells and intestinal epithelial cells, while pERK1/2 was expressed in the cytoplasm and nucleus of goblet cells and intestinal epithelial cells. The immunolocalization of ERK1/2 and pERK1/2 expression were more obvious in the non-breeding season, especially in intestinal epithelial cells. The results of real-time quantitative PCR and Western blot showed that the expression of ERK $1 / 2$ and pERK1/2 in the breeding season was significantly lower than that in the non-breeding season.

Conclusions: The expression of ERK $1 / 2$ and pERK $1 / 2$ in the colons of the wild ground squirrels had seasonal changes, which had significant increases in the non-breeding season comparing to those in the breeding season. This study revealed the potential role of ERK $1 / 2$ in colon to the adaptation of seasonal changes in wild ground squirrel.

\section{Background}

Mitogen-activated protein kinase (MAPK) is an important family of protein kinases in eukaryotic cells. Extracellular signal regulated kinases (ERKs) are important members of the MAPKs family. ERK1 and ERK2 are the first reported MAPKs. They share $84 \%$ in common and share many common function ${ }^{[1]}$, so usually, they are called ERK1/2. At the level of mRNA, ERK1/2 is often referred to as MAPK1/3.

ERK1/2 can regulate cell cycle progression, proliferation, cytokinesis, transcription, differentiation, cell death, migration, gap junction. In addition to these functions, ERK $1 / 2$ are also key enzymes in the development of the immune system, the development of the nervous system, memory formation, and heart development ${ }^{[2-5]}$.

ERK stimulating factors bind to receptors on the cell surface to activate the Ras pathway and then interact with downstream kinase Raf. Activated Raf binds and phosphorylates MAPKK. Activated MAPKK phosphorylates threonine and tyrosine in the conserved structure of Thr-Glu-Tyr (TEY) in the activation ring of ERK $1 / 2$ and the bind to downstream substrates ${ }^{[6]}$.

The target sites of ERKs vary in location and function and include cytoplasmic, nuclear, and membrane proteins that encode transcription factors, RNA-binding proteins, or signaling proteins. After receiving external stimulation, ERK, which is widely distributed in the cell, is phosphorylated to pERK and moves 
toward the target. This is generally considered to be the activation of the ERK pathway. Phosphatase dephosphorylates and inactivates extracellular signal regulated kinases, thereby closing this pathway ${ }^{[7]}$.

ERKs play important roles in nerve cell protection. Activation of ERKs is a pathway to induce the growth of nerve axons ${ }^{[8]}$. In tumor and cancer, aspirin can promote the enhancement of TNF-related apoptosisinducing ligand (TRAIL) significantly, and a combination of TRAIL can significantly inhibit ERK $1 / 2$ activation and enhance TRAIL-induced apoptosis ${ }^{[9]}$. In human colon cancer cell lines Caco2 cultured in vitro, the increased level of activated phosphorylated ERK1/2 promoted cell proliferation. In addition, Caco2 tumor cells could spontaneously differentiate into intestinal epithelial cells to form clones, and the differentiation of Caco2 cells was also affected after treatment with MAPKK inhibitor ${ }^{[10]}$. ERK $1 / 2$ is also related to the differentiation of the intestinal cell population, and the activation of ERK $1 / 2$ inhibits the transcription of the sucrose-maltose gene induced by caudal-related homeobox transcription factor $2 / 3$ (CDX2/3), thereby inhibiting the differentiation of intestinal epithelium ${ }^{[11]}$. Eric's study found that in the kirsten rat sarcoma viral oncogene (KRAS) mutant mice, the intestinal epithelial cells multiplied, the Panthera cells reduced, and the differentiation of goblet cells increased. The results suggested that ERK signaling pathway may be involved in determining intestinal prosses of cell differentiation in Panthera cells and goblet cells ${ }^{[12]}$. The gut microbiota can change the content of androgen in the blood of female mice through the Hypothalamic-Pituitary-Gonadal axis (HPGA), which indirectly leads to the occurrence of polycystic ovary syndrome $e^{[13]}$.

The wild ground squirrel (Spermophilus dauricus) has the characteristic of the typical seasonal reproduction, which made it a good material for studying seasonal reproduction ${ }^{[14]}$. Usually they enter the breeding season from April to May, followed by several months of activity, and their hibernation begins in October ${ }^{[15-16]}$. Up to the date, there is no related study between the expression of ERK $1 / 2$ in the colon and wild ground squirrels. This study focused on the expression of ERK $1 / 2$ in the colon to explore the relationship between colonic ERK1/2 expression and seasonal adaption in the wild ground squirrel.

\section{Materials And Methods}

\subsection{Animals and tissues}

Wild ground squirrels were captured in the breeding season and non-breeding season in Hebei Province, China. The treatment of animals was observed AVMA(American Veterinary Medical Association) Guidelines for the Euthanasia of Animals: 2020 Edition (https://www.avma.org/sites/default/files/202002/Guidelines-on-Euthanasia-2020.pdf). Animals were placed in a container with slow passage of carbon dioxide until the animals were in a recumbent position, and then quickly killed via decapitation. And all animal experiments were approved by the Policy on the Care and Use of Animals by the Ethical Committee of Beijing Forestry University and the Department of Agriculture of Hebei Province, China (JNZF11/2007). Colonic tissues were extracted. Half of the colons of the squirrels were fixed with $4 \%$ paraformaldehyde for $48 \mathrm{~h}$, washed with running water for $24 \mathrm{~h}$ and stored in $70 \%$ alcohol. The other half 
samples were quickly placed in liquid nitrogen and transferred to a $-80^{\circ} \mathrm{C}$ refrigerator for later extraction of RNA and proteins.

\subsection{Antibodies}

The primary antibodies were utilized in this study, including the rabbit polyclonal anti-ERK1/2 (BS-2637R, Beijing Biosynthesis Biotechnology Co., Ltd., Beijing, China), rabbit polyclonal anti-pERK1/2 (BS-3016R, Beijing Biosynthesis Biotechnology Co., Ltd., Beijing, China), and $\beta$-actin (BS-0061R, Beijing Biosynthesis Biotechnology Co., Ltd., Beijing, China). The dilution of ERK1/2 and pERK1/2 antibodies for immunohistochemistry and Western blot observations were respectively 1:200 and 1:750, and the dilution of $\beta$-actin antibodies for Western blot observations was 1:1000.

\subsection{Histology}

The colonic tissues were embedded in paraffin wax after dehydrated in ethanol series. Slides coated with poly-L-lysine (Sigma-Aldrich, St. Louis, MO, USA) were used to set serial sections $(6 \mu \mathrm{m})$. The serial sections were stained with hematoxylin-eosin (HE) for general histological analysis.

\subsection{Immunohistochemistry}

The serial sections of colonic tissues were boiled in citrate buffer and blocked with $10 \%$ normal goat serum. The sections were then incubated with the primary antibody overnight at $4^{\circ} \mathrm{C}$. Subsequent incubations were utilized by the secondary antibody, goat anti-rabbit IgG conjugated with biotin and peroxidase with avidin using SP Kit (Rabbit) (SP-0023, Beijing Biosynthesis Biotechnology Co., Ltd., Beijing, China), then following by the visualization with $30 \mathrm{mg}$ 3,3-diaminobenzidine (Wako, Tokyo, Japan) solution in $150 \mathrm{~mL}$ of $0.05 \mathrm{Mol}$ Tris- $\mathrm{HCl}$ buffer, $\mathrm{pH}$ 7.6, plus $30 \mu \mathrm{L} \mathrm{H}_{2} \mathrm{O}_{2}$. The reacted sections for ERK1/2 and pERK1/2 were counterstained with hematoxylin solution (Merck, Tokyo, Japan).

\subsection{Total RNA isolation and real-time quantitative PCR}

The colonic tissues were utilized to obtain Total RNA by Trizol® Reagent (Invitrogen, Carlsbad, CA, USA). About $0.1 \mathrm{~g}$ of each sample was thawed and immediately homogenized in $1 \mathrm{~mL}$ of TRIzol ${ }^{\mathrm{TM}}$ Reagent to dissociate nucleoprotein complexes. $0.2 \mathrm{~mL}$ of chloroform was added into the homogenate. Then, the mixture was vigorously shaken for $15 \mathrm{sec}$ at room temperature and centrifuged at $12,000 \mathrm{~g}$ for $20 \mathrm{~min}$ at $4{ }^{\circ} \mathrm{C}$. The aqueous phase was diverted to RNase free tube. $500 \mu \mathrm{L}$ of isopropanol was added. The solutions were kept for $10 \mathrm{~min}$ at room temperature and centrifuged at $12,000 \mathrm{~g}$ for $20 \mathrm{~min}$ at $4^{\circ} \mathrm{C}$. Then, RNA was precipitated, washed twice with $70 \%$ ethanol, and dissolved in diethylpyrocarbonate-treated water $(30 \mu \mathrm{L})$. The concentration and quality were analyzed by spectrophotometer (NanoDrop 2000, Thermo Fisher Scientific, Waltham, MA, USA). The mRNA concentration in different samples was adjusted to $250 \mathrm{ng} / \mathrm{mL}$ and the first-strand cDNA from total RNA was synthesized using GoScript reverse transcription system (Promega Corporation, Madison, WI, USA) and random primer according to the manufacturer's protocol. The primers sequence used for mRNA qRT-PCR were shown in Table 1. The PCR 
reactions were carried out in a $10 \mu \mathrm{L}$ volume using FastStart DNA MasterPlast SYBR green kit (Roche Molecular Systems Inc., Basel, Switzerland) and performed with ABI PRISM 7500 Fast Real-Time PCR System (Applied Biosystems, Foster City, CA, USA). The following listed conditions were used: preincubation at $95^{\circ} \mathrm{C}$ for $10 \mathrm{~min}$, then amplification at $95^{\circ} \mathrm{C}$ for $30 \mathrm{~s}, 60^{\circ} \mathrm{C}$ for $30 \mathrm{~s}$ and $72{ }^{\circ} \mathrm{C}$ for $30 \mathrm{~s}$, followed by PCR reaction of 40 cycles, and then melting step at $60^{\circ} \mathrm{C}$.

Table 1 The primers sequence used for mRNA qRT-PCR

\begin{tabular}{lll} 
Gene name & Sequence of primer & Product size (bp) \\
\hline MAPK1 & F:5'TGGTTCCTCCCACTCCTGAA3' & 142 \\
& R:5'TGGGCAAATAGCACACACCT3' & \\
\hline MAPK3 & F:5'ACTACCTGGACCAGCTCAAC3' & 305 \\
& R:5'GCTTGTTGGGGTTGAAGGTT5' \\
\hline \multirow{2}{*}{ B-actin } & F:5'GACTCGTCGTACTCCTGCTT3' & 223 \\
& R:5'AAGACCTCTATGCCAACACC3' &
\end{tabular}

2.6 Protein extraction and Western blot analysis

Protein was extracted from the colonic tissues of the wild ground squirrels. Colonic tissues were diced into small pieces, solubilized in $1 \mathrm{~mL}$ Radio-Immunoprecipitation Assay (RIPA) lysis buffer (0.5\% sodium deoxycholate, $150 \mathrm{mM} \mathrm{NaCl}, 1 \%$ Nonidet P 40, $50 \mathrm{mM}$ Tris (pH 7.4)) with $10 \mu \mathrm{L}$ phenylmethylsulfonyl fluoride (PMSF) $(10 \mathrm{mg} / \mathrm{mL}$ ), homogenized by an ultrasonic homogenizer (Scientz, Ningbo, Zhejiang, China), and then incubated on ice for $30 \mathrm{~min}$. Homogenates were centrifuged at $12,000 \mathrm{~g}$ for $10 \mathrm{~min}$ at 4 ${ }^{\circ} \mathrm{C}$, and then the supernatant was collected. All protein extraction processes were performed on ice or maintaining the temperature at $4{ }^{\circ} \mathrm{C}$. Protein extracts were mixed with an equal volume of $2 \times$ LaemmLi's sample buffer, analyzed by a $15 \%$ SDS-polyacrylamide gels (SDS-PAGE) at $18 \mathrm{~V} / \mathrm{cm}$, and transferred to nitrocellulose membranes. The membranes were blocked with $2 \%$ BSA for $1 \mathrm{hr}$ at room temperature followed by overnight incubation with 1:200 primary antibodies. Secondary incubation of the membranes was performed by secondary antibodies (goat anti-rabbit IgG for ERK1/2 and pERK1/2, goat anti-mouse IgG for $\beta$-actin) tagged with horseradish peroxidase for $1 \mathrm{hr}$. The membranes were stained with diaminobenzidine after being washed three times in $50 \mathrm{~mL}$ TTBS (Tris-buffered saline with Tween 20) buffer $(0.137 \mathrm{M} \mathrm{NaCl}, 0.02 \mathrm{M}$ Tris and 0.1\% Tween-20, pH 7.6).

\subsection{Statistical analysis}

The quantitative data were obtained by the experiments and statistical analyses were performed using GraphPad Prism 5.0 (GraphPad Software Inc., San Diego, CA, USA). The difference between groups was compared using the Student's t-test. Statistical values of $\mathrm{P}<0.05$ were considered significant. 


\section{Results}

3.1. Histological changes of the colons of wild ground squirrels

Histological results of colonic tissues of wild ground squirrel during the breeding season and nonbreeding season were shown in Fig. 1, and details were shown in Fig. 2. The comparison between Fig. 1a and Fig. $1 \mathrm{~b}$ showed that the lumen diameter of the colonic tissue was significantly smaller in the breeding season than those in the non-breeding season, and the number of goblet cells (GC) in the breeding season was less than those in the non-breeding season.

\subsection{Immunolocalization of ERK1/2 and pERK1/2 in the colon of wild ground squirrels}

Immunohistochemical staining for ERK $1 / 2$ and pERK1/2 was performed in the colons between the breeding and non-breeding seasons respectively in Fig. 3. Both ERK1/2 and pERK1/2 were observed in the cytoplasm of the GC and epithelial cell $(E C)$ between the breeding and non-breeding seasons. pERK1/2 was observed in the cytoplasm and nuclear of GC and EC between the breeding and nonbreeding seasons. Furthermore, during the non-breeding season (Fig. 3e-f), staining signal of ERK1/2 and pERK1/2 were higher than that in the breeding season (Fig. 3b-c). No positive signal was found in the negative controls (Fig. 3a, d).

\subsection{Seasonal expression of ERK $1 / 2$ and pERK1/2 in the colons of wild ground squirrels}

The mRNA and protein expression patterns in the colons between the breeding and non-breeding seasons were shown in Fig. 4 and Fig. 5, respectively. The mRNA expression levels of MAPK1 and MAPK3 in the colons were significantly higher in the non-breeding season than those in the breeding season (Fig. 4). Furthermore, compared with the breeding season, the protein expression levels of ERK $1 / 2$ and pERK $1 / 2$ in the colons were significantly higher in the non-breeding season (Fig. 5).

\section{Discussion}

In this study, the localization and expression of ERK1/2 and pERK1/2 in the colonic tissue of wild ground squirrels in the breeding season and the non-breeding season were explored, using hematoxylin-eosin staining, immunohistochemistry, real-time quantitative PCR and Western blot. The experimental results showed that in the non-breeding season, the lumen diameter of the colon has increased significantly and the number of GC has increased. From the histologic results we speculated that to adapt to the energy demand of the seasonal reproduction, the colon of wild ground squirrel has enlarged. While in the nonbreeding season, the energy demand of reproductive system has reduced, then the colon lumen enlarge. Using immunohistochemistry, quantitative real-time PCR and Western blot, the expression position and intensity of the ERK $1 / 2$ in the colon were preliminary explored, which laid a foundation for the subsequent study on the effect of the expression of ERK $1 / 2$ pathway in the colon on seasonal reproduction. Immunohistochemical results showed that ERK1/2 was expressed in the cytoplasm of GC 
and intestinal EC, while pERK1/2 was also expressed in the nucleus of both types of cells, suggesting that ERK1/2 had migrated from the cytoplasm to the nucleus after activation of the ERK1/2 pathway. The results of Western blot showed that the expression levels of ERK $1 / 2$ and pERK $1 / 2$ in the colonic breeding season of wild ground squirrels were lower than those in the non-breeding period, and the differences were significant.

ERK1/2 can regulate a vary of cell processes and phylogeny. Research on the colon ERK1/2 signaling pathway has focused on colon cancer. The high expression of pERK $1 / 2$ in intestinal EC is a marker of early colon cancer ${ }^{[17]}$. The study on the new drug Enduo showed that the drug had a certain therapeutic effect on colon cancer by blocking the ERK signaling pathway to prevent cell migration ${ }^{[18]}$. Verticillin $A$ increases the ratio of BIMEL/MCL-1 to overcome ABT-737-resistance in human colon cancer cells by targeting the MEK/ERK pathway ${ }^{[19]}$. PKCa activated RAS upstream of RAF, MEK and ERK, which induced the arrest of the cell cycle in intestinal cells ${ }^{[20]}$. Studies have shown that the Wnt/ $\beta$-catenin signaling pathway has a synergistic effect with the ERK1/2 pathway to some extent. For example, the low expression of the long non-coding RNA Casc2c associated with gastric cancer in gastric cancer tissues may lead to decreased expression levels of the ERK1/2 pathway and the Wnt/ $\beta$-catenin signaling pathway ${ }^{[21]}$. To inhibit the proliferation and migration of gastric cancer cells. In other studies on the testis of wild ground squirrels, it was found that the activin signaling pathway can also cross-interact with the ERK1/2 pathway, thus participating in the regulation of cell proliferation and apoptosis ${ }^{[22]}$.

Previous morphological observations showed that the diameter of colons of wild ground squirrels in the non-breeding season was larger than those in the breeding season. This kind of change was the seasonal adaption of colonic tissues to the environment. The wild ground squirrel distributes its energy through seasonal reproduction to ensure that the animals reproduce in the most favorable living environment and the best physical condition. At present, most of the researches on seasonal adaption is focused on the reproductive system and its neuro-humoral regulation. There is little research on the influence of various systems, especially the digestive system on seasonal adaption. Studies have shown that the reproductive system generally produces seasonal changes in the process of seasonal reproduction. The weight of reproductive organs in the breeding season is higher than that in the non-breeding season, and sperm generation can only occur in the testis of males during the breeding season ${ }^{[16]}$. In females, all types of follicles and luteum exist only in the ovary during the breeding season ${ }^{[23]}$. As mentioned above, ERK1/2 can regulate cell progression, and regulates phylogeny. These roles may provide new ideas for the explanation of seasonal changes in the colon. This study initially analyzed the relationship between the expression of the ERK1/2 pathway in the colonic tissue and seasonal adaption.

In recent years, studies related to the upstream and downstream regulation of the ERK pathway have also been developed in different tissues and cells. Calcium-sensing receptors (CaSR) were involved in the induction of kidney calculi related proteins. Calculi related proteins and ERK were upregulated in the kidney of rats treated with Calcium oxalate and cell apoptosis may lead to crystal adhesion on the surface of kidney cells to form calculi ${ }^{[24]}$. MicroRNAs (miRNAs) are important regulatory factors of gene 
expression, which play a key role in the occurrence and development of tumors and can also regulate ERK signal, which is usually overexpressed in cancerous tissues. Study showed that the regulation of the ERK

signaling pathway by miRNAs plays an important role in the development of cancer ${ }^{[25]}$. Venezuelan equine encephalitis virus (VEEV) can infect primary astrocytes by upregulation of Early Growth Response 1 (EGR1) induces cell apoptosis and viral transcription. ERK1/2 gene knockout significantly reduced the expression of EGR1, and the ERK1/2 pathway plays a key role in astrocyte apoptosis. ERK pathway is an important link in the formation of osteoblasts and bone metabolism ${ }^{[26]}$.

The experiment verified the lumen of wild ground squirrel colons had seasonal changes by the results of immunohistochemistry and Western blot which can significantly observe the differences of colon breeding season. Because of the lack of research on ERK downstream in this study, it can be speculated that there may be a certain correlation between the seasonal expression of ERK $1 / 2$ and seasonal reproduction, which may provide basic data for the study of the relationship between the colon and seasonal reproduction. The specific regulatory mechanism needs further research.

\section{Conclusion}

The expression of ERK1/2 and pERK1/2 in the colons of the wild ground squirrels had seasonal changes, which had significant increases in the non-breeding season comparing to those in the breeding season. ERK1/2 was expressed in the cytoplasm of GC and EC, while pERK $1 / 2$ was also expressed in the nucleus of both types cells.

\section{Declarations}

Funding (information that explains whether and by whom the research was supported)

This research work is supported by the Fundamental Research Funds for the Central Universities (2018ZY21), and the National Training Program of Innovation and Entrepreneurship for Undergraduates (202010022079, 202010022072).

\section{Conflicts of interest/Competing interests (include appropriate disclosures)}

The authors declare that they have no competing financial interests or personal relationships that could have appeared to influence the work reported in this paper.

\section{Availability of data and material (data transparency)}

All data generated or analyzed during this study are included in this published article.

\section{Code availability (software application or custom code)}

Not applicable. 


\section{Authors' contributions}

Yue Song: Participated in sample collection, Performing the experiments, Assisted with all experiments, Analyzing the data, Drafting the manuscript.

Xiaoying Yang: Participated in sample collection, Performing the experiments, Assisted with all experiments, Analyzing the data.

Xueying Zhang: Participated in sample collection, Performing the experiments.

Jueyu Zhu: Participated in sample collection, Performing the experiments.

Yixin Chen: Participated in sample collection.

Fuli Gao: Assisted with all experiments, Helped revising the manuscript.

Haolin Zhang: Assisted with all experiments, Helped revising the manuscript.

Yingying Han: Helped revising the manuscript.

Qiang Weng: Designed, Supervised the study, Revised manuscript.

Zhengrong Yuan*: Designed, Supervised the study, Revised manuscript.

\section{Ethics approval (include appropriate approvals or waivers)}

All animal procedures were approved by the Policy on the Care and Use of Animals by the Ethical Committee, Beijing Forestry University and the Department of Agriculture of Hebei Province, China (JNZF11/2007).

\section{Consent to participate (include appropriate statements)}

Not applicable.

\section{Consent for publication (include appropriate statements)}

Submission of an article implies that the work described has not been published previously, that it is not under consideration for publication elsewhere, that its publication is approved by all authors and tacitly or explicitly by the responsible authorities where the work was carried out, and that, if accepted, it will not be published elsewhere in the same form, in English or in any other language, including electronically without the written consent of the copyright-holder.

\section{Acknowledgements}

This research work is supported by the Fundamental Research Funds for the Central Universities (2018ZY21), and the National Training Program of Innovation and Entrepreneurship for Undergraduates 


\section{References}

1. Lloyd AC (2006) Distinct functions for ERKs? J Biol 5:13. https://doi.org/10.1186/jbiol46

2. Saba-El-Leil MK, Vella F, Vernay B, Voisin L, Chen L, Labrecque $N$ et al (2003) An essential function of the mitogen-activated protein kinase ERK2 in mouse trophoblast development. EMBO Rep 4:964968. https://doi.org/10.1038/sj.embor.embor939

3. Ramos JW (2008) The regulation of extracellular signal-regulated kinase (ERK) in mammalian cells. Int J Biochem Cell Biol 40:2707-2719. https://doi.org/10.1016/j.biocel.2008.04.009

4. Xu B, Yang L, Lye RJ, Hinton BT (2010) p-MAPK1/3 and DUSP6 regulate epididymal cell proliferation and survival in a region-specific manner in mice. Biol Reprod 83:807-817. https://doi.org/10.1095/biolreprod.110.085613

5. Xu B, Abdel-Fattah R, Yang L, Crenshaw SA, Black MB, Hinton BT (2011) Testicular Lumicrine Factors Regulate ERK, STAT, and NFKB Pathways in the Initial Segment of the Rat Epididymis to Prevent Apoptosis. Biol Reprod 84:1282-1291. https://doi.org/10.1095/biolreprod.110.090324

6. Kolch W (2005) Coordinating ERK/MAPK signalling through scaffolds and inhibitors. Nat Rev Mol Cell Biol 6:827-837. https://doi.org/10.1038/nrm1743

7. Hoshino R, Chatani Y, Yamori T, Tsuruo T, Kohno M (1999) Constitutive activation of the 41-/43-kDa mitogen-activated protein kinase signaling pathway in human tumors. Oncog 18:813-822. https://doi.org/10.2514/2.1049

8. Kang YS, Bae MK, Kim JY, Jeong JW, Bae SK (2011) Visfatin induces neurite outgrowth in PC12 cells via ERK1/2 signaling pathway. Neurosci Lett 504:121-126. https://doi.org/10.1016/j.neulet.2011.09.014

9. Im SR, Jang YJ (2012) Aspirin enhances TRAIL-induced apoptosis via regulation of ERK1/2 activation in human cervical cancer cells. Biochem Biophys Res Commun 424:65-70. https://doi.org/10.1016/j.bbrc.2012.06.067

10. Aliaga JC, Deschênes C, Bea U, Calvo EL, Rivard N (1999) Requirement of the MAP kinase cascade for cell cycle progression and differentiation of human intestinal cells. Am J Physiol 277:631-641. https://doi.org/10.1016/S0034-5687(99)00052-3

11. Lemieux E, Boudreau F, Rivard N (2011) Constitutive activation of the MEK/ERK pathway inhibits intestinal epithelial cell differentiation. Am J Physiol Gastrointest Liver Physiol 136: A-394-A-394. https://doi.org/10.1016/S0016-5085(09)61810-2

12. Ying F, Bommer GT, Zhao J, Green M, Sands E, Zhai Y et al (2011) Mutant KRASpromotes hyperplasia and alters differentiation in the colon epithelium but does not expand the presumptive stem cell pool. Gastroenterol 141:1003-1013.e10. https://doi.org/10.1053/j.gastro.2011.05.007

13. Janet GMM, Daniel NF, Steven M, Charles ER, Leah MF, Ulrike R et al (2013) Sex Differences in the Gut Microbiome Drive Hormone-Dependent Regulation of Autoimmunity. Sci 339:1084-1088. 
https://doi.org/10.1126/science.1233521

14. Han Y, Zhan J, Ying X, Zhang F, Qiang W (2016) Proliferation and apoptosis processes in the seasonal testicular development of the wild Daurian ground squirrel (Citellus dauricus Brandt, 1844). Reprod Fertil Dev 29:1680-1688. https://doi.org/10.1071/RD16063

15. Zhang M, Sheng X, Sun R, Li Q, Taya K (2013) Seasonal changes in immunoreactivity of inhibin/activin subunits in the epididymis of wild ground squirrels (Citellus dauricus brandt). J Reprod Dev 59:302-307. https://doi.org/10.1262/jrd.2012-141

16. Wang J, Ying W, Zhu M, Zhang F, Qiang W (2017) Seasonal expression of luteinizing hormone receptor and follicle stimulating hormone receptor in testes of the wild ground squirrels (Citellus dauricus brandt). Acta Histochem 119: JOE-17-0079. https://doi.org/10.1016/j.acthis.2017.09.004

17. Amsterdam A (2013) Two initiation sites of early detection of colon cancer, revealed by localization of pERK $1 / 2$ in the nuclei or in aggregates at the perinuclear region of tumor cells. Int $\mathrm{J}$ Oncol 115:569-576. https://doi.org/10.1016/j.acthis.2012.12.006

18. Idiiatullina E, Al-Azab M, Walana W, Pavlov V, Liu B (2021) EnDuo, a novel derivative of Endostar, inhibits the migration of colon cancer cells, suppresses matrix metalloproteinase-2/9 expression and impedes AKT/ERK activation. Biomed Pharmacother 134:111136.

https://doi.org/10.1016/j.biopha.2020.111136

19. Guan YL, Tu K, Huang QQ, Liu FY (2021) Verticillin a increases the bim el /mcl-1 ratio to overcome abt-737-resistance in human colon cancer cells by targeting the MEK/ERK pathway. Biochem Biophys Res Commun 567: 22-28. https://doi.org/ 10.1016/J.BBRC.2021.05.103

20. Kaur N, Lewis R, Black A, Black J (2021) A Growth Inhibitory PKCa-ERK Signaling Pathway In the Intestine/Colon. FASEB J 35:04156. https://doi.org/10.1158/1538-7445.AM2018-3466

21. Li QY, Yang K, Liu FG, Sun XG, Chen L, Xiu H et al (2020) Long noncoding RNA CASC2c inhibited cell proliferation in hepatocellular carcinoma by inactivated ERK1/2 and Wnt/ $\beta$-catenin signaling pathway. Clin Transl Oncol 22:302-310. https://doi.org/10.1007/s12094-019-02223-7

22. Levidou G, Saetta AA, Gigelou F, Karlou M, Papanastasiou P, Stamatelli A et al (2012) ERK/pERK expression and B-raf mutations in colon adenocarcinomas: correlation with clinicopathological characteristics. World J Surg Oncol 10:47. https://doi.org/10.1186/1477-7819-10-47

23. Wang Y, Yao Y, Zhang C, Guo Y, Weng Q (2019) Seasonal expressions of COX-1, COX-2 and EP4 in the uteri of the wild daurian ground squirrels (Spermophilus dauricus). Prostaglandins Other Lipid Mediat 143:106343. https://doi.org/10.1016/j.prostaglandins.2019.106343

24. Li XR, Chen SY, Feng DM, Fu YQ, Wu H, Lu JZ et al (2021) Calcium-sensing receptor promotes calcium oxalate crystal adhesion and renal injury in Wistar rats by promoting ROS production and subsequent regulation of PS ectropion, OPN, KIM-1, and ERK expression. Ren Fail 43:465-476. https://doi.org/10.1080/0886022X.2021.1881554

25. Eraab G, Ma B, Sn B, Bmbc D, Am B, Am C et al (2021) Interplay between MAPK/ERK signaling pathway and MicroRNAs: A crucial mechanism regulating cancer cell metabolism and tumor progression. Life Sci 278:119499. https://doi.org/10.1016/j.Ifs.2021.119499 
26. Dahal B, Lin SC, Carey BD, Jacobs JL, Dinman JD, Hoek M et al (2020) EGR1 upregulation following Venezuelan equine encephalitis virus infection is regulated by ERK and PERK pathways contributing to cell death. Elsevier Public Health Emerg Collect 539:121-128.

https://doi.org/10.1016/j.virol.2019.10.016

\section{Figures}

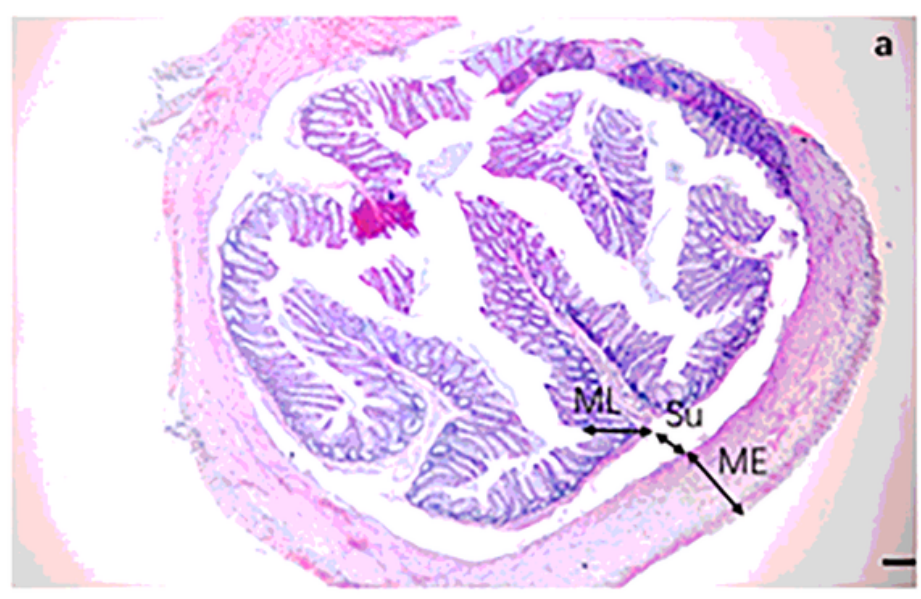

B
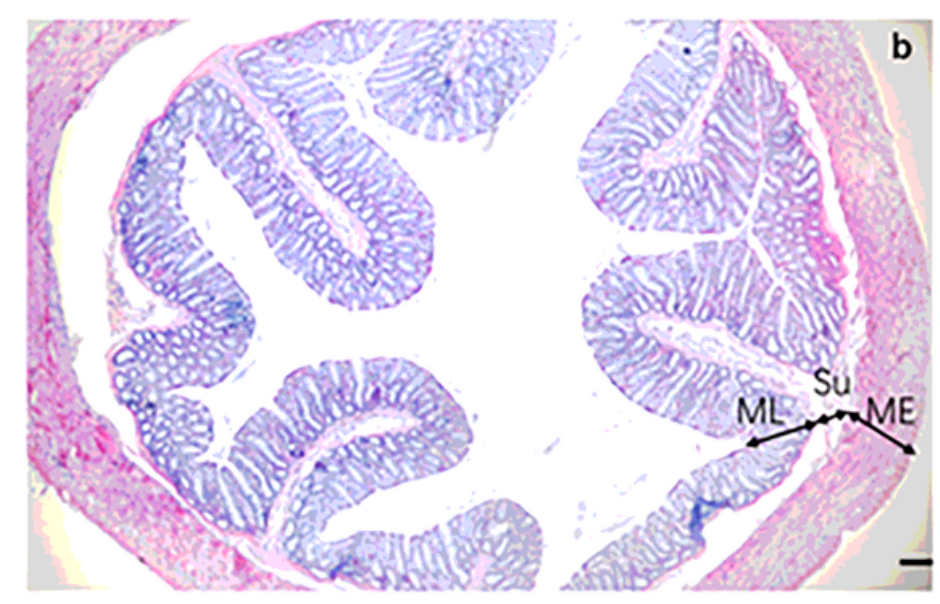

NB

\section{Figure 1}

Histological structure of the colon by hematoxylin-eosin (HE). Histological observations of the colons in the breeding season (a) and the non-breeding season (b). Scale bars $=100 \mu \mathrm{m}$. Abbreviations: $\mathrm{B}$, the breeding season; NB, the non-breeding season; ME, muscular elements; ML, mucous layer; $\mathrm{Su}$, submucosa 


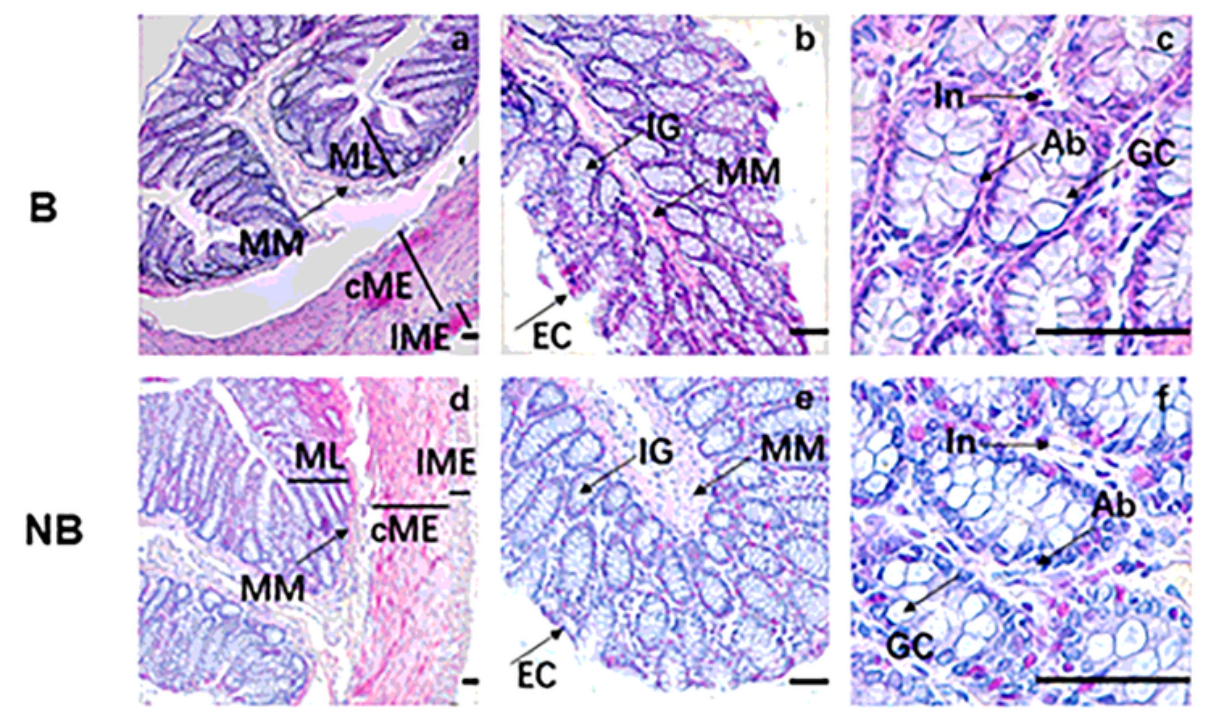

Figure 2

Detailed histological structure of the colon by hematoxylin-eosin (HE). Histological observations of the colons in the breeding season (a-c) and the non-breeding season (d-f). Scale bars $=50 \mu \mathrm{m}$. Abbreviations: $B$, the breeding season; NB, the non-breeding season; $A b$, absorptive cell; $C M E$, circular muscular elements; EC, epithelial cell; GC, goblet cell; In, interstitial cell; IME, longitudinal muscular elements; IG, intestinal glandML, mucous layer; MM, muscularis mucosa

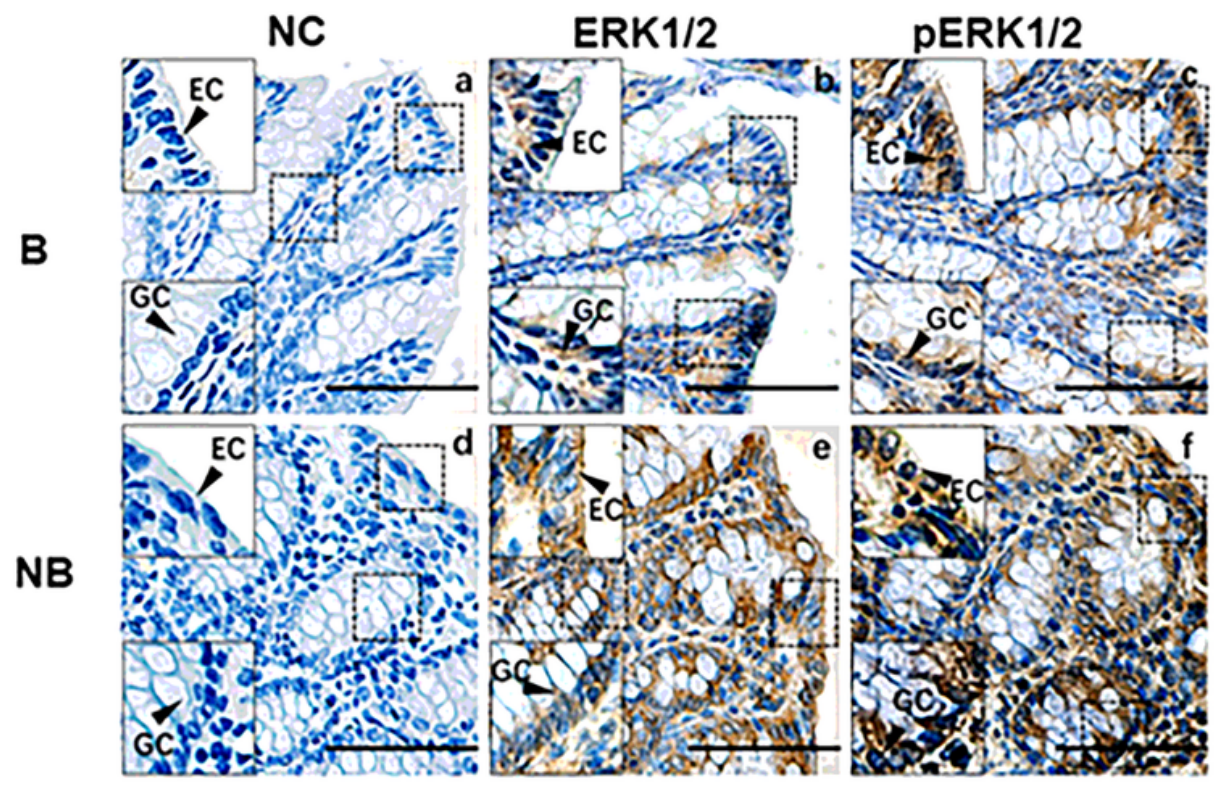

Figure 3 
Seasonal immunolocalization of ERK $1 / 2$ and pERK $1 / 2$ in the colons of the wild ground squirrels between the breeding and non-breeding seasons. Immunolocalization of ERK1/2 in the colons (b-c).

Immunolocalization of pERK $1 / 2$ in the colons (e-f). Negative control $(a, d)$. The first row (a-c) represents staining in the breeding season. The second row (d-f) represents staining in the non-breeding season.

Scale bars represent $50 \mu \mathrm{m}$ (a-f). Abbreviations: B, the breeding season; NB, the non-breeding season; NC, Negative control; ERK1/2, Extracellular signal-regulated protein kinase1 and 2; pERK1/2, Phosphoextracellular signal-regulated protein kinase 1 and 2; EC, epithelial cell; GC, goblet cell

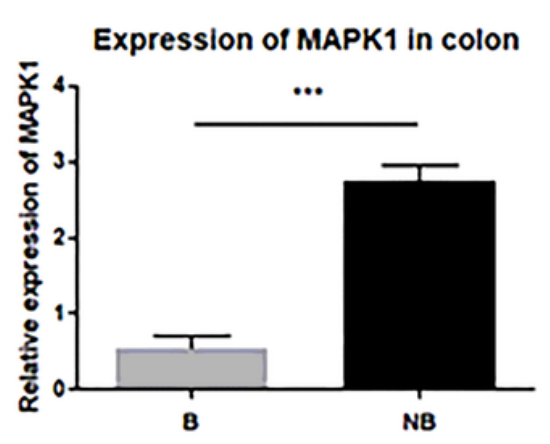

a

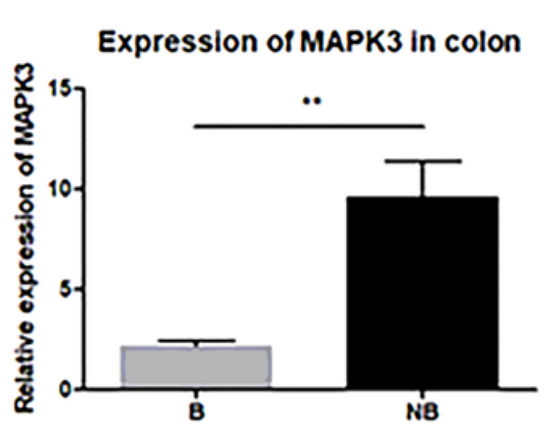

Figure 4

Expression levels of MAPK1 (a) and MAPK3 (b)

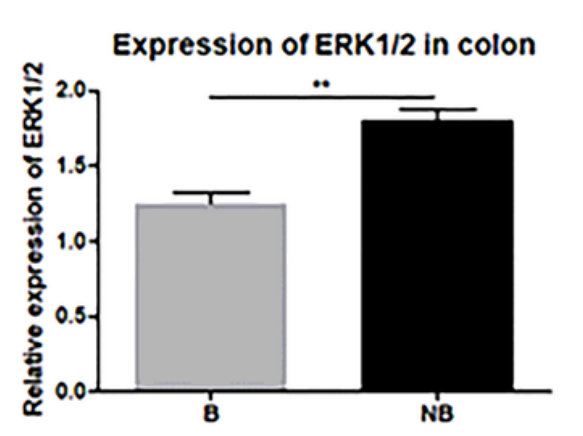

a

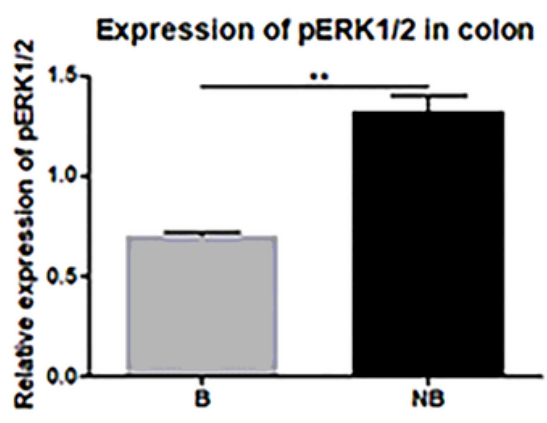

b

c

ERK1/2

$42 / 44 \mathrm{kDa}$

PERK1/2

$41 \mathrm{kDa}$

$\beta$-actin

$42 \mathrm{kDa}$

B1 B2 B3 NB1 NB2 NB3 
Figure 5

Expression levels of ERK1/2 (a) and pERK1/2 (b)

\section{Supplementary Files}

This is a list of supplementary files associated with this preprint. Click to download.

- PDFversionofthearticleforsupplementarymaterial.pdf 